MATERIALS CHARACTERIZATION 60 (2009) 636-643

\title{
Developing a future repairs strategy for a sandstone city: A petrographic investigation of building stone in Glasgow, Scotland
}

\author{
Ewan K. Hyslop \& Luis Albornoz-Parra \\ British Geological Survey, Murchison House, West Mains Road, Edinburgh EH9 3LA, United Kingdom \\ Corresponding author. E-mail address: ekh@bgs.ac.uk (E.K. Hyslop).
}

\begin{abstract}
Glasgow is the largest city in Scotland, and has some of the finest historic stone architecture in the United Kingdom. All the building stone quarries in the Glasgow area are closed and stone for repairs is now imported. Six types of 'blonde' sandstone and four types of 'red' sandstone have been identified from petrographic analysis of 126 samples from traditional buildings throughout the city. Currently available stone types from active quarries have been identified which have similar characteristics, in order to ensure compatibility of long-term performance for repairs. A number of the original sandstone types do not match with stone currently being quarried, and there is a need to reopen historic quarries, or new quarries which can supply similar stone. The data provide a framework to improve decision-making in the selection of appropriate stone for repairs to ensure the future long-term health of historic buildings in the city of Glasgow.
\end{abstract}

Keywords: Sandstone, Petrography, Stone-matching, Quarries

\section{Introduction}

Glasgow is recognised as having some of the finest Victorian architecture in the United Kingdom. As the industrial and commercial capital of Scotland it saw a rapid expansion from the late 18th century, through the 19th century and into the early 20th century, initially from the shipping and merchant trade and latterly through industrial production and manufacturing. Stone was the building material of choice, and the rapid urban growth resulted in a wide range of building types, from utilitarian high density residential blocks (tenements) to elegant terrace and villa developments, schools, churches, public and commercial buildings. By the 1890s Glasgow was known as the 'Sixth City of Europe' with some of the finest examples of architecture of its time.

Glasgow is a city characterised by sandstone, dominated by the locally-available pale-or cream-coloured 'blonde' sandstones of Carboniferous age. Following the arrival of the railways, 'red' sandstone of Permian/Triassic age was used from the mid-1880s, imported from quarries further to the south in Ayrshire and Dumfriesshire. By the early 20th century, red sandstone had become favoured for many public buildings, schools, churches and tenement fronts, and became important in the latter stages of stone construction in the city.

Today, many of Glasgow's buildings are of an age and condition where the masonry is showing signs of decay and requires repair. A legacy of former air pollution from industrial sources and domestic coal burning has accelerated stone decay in many parts of the city. Further significant deterioration of sandstone has been caused by inappropriate intervention and poor quality repairs. Stone cleaning, much of which took place during large-scale public-funded urban regeneration schemes in the second part of the 
20th century, has resulted in widespread damage [1,2]. The proliferation of so-called 'plastic' repairs using impervious cement materials applied to the softer porous sandstones, often to stone damaged by stonecleaning, has also resulted in considerable damage. The extensive use of these techniques in the second half of the 20th century has created a situation where many stone buildings in the city are now in need of urgent attention and stone replacement.

This paper describes results of a petrographic investigation of sandstone samples from buildings in Glasgow, undertaken as part of a recent large-scale project which was carried out to assess the future stone masonry skills and the stone materials needed to conserve and repair the stone-built heritage of Glasgow over the next 20 years. It is recognised that a shortage in the availability of stonemasonry skills and training, and a lack of supply of appropriate 'matching' stone for repairs is having a detrimental impact on the stone-built heritage of Glasgow, and Scotland in general. To address this issue the project 'Safeguarding Glasgow's Stone Built Heritage: Skills and Materials Requirements' was established by the Scottish Stone Liaison Group (SSLG), commissioned by Scottish Enterprise Glasgow. The British Geological Survey (BGS) was appointed to undertake stone condition surveys and petrographic analysis of stone samples, and it is these latter studies that are described in this paper. The full results of the project are published in a detailed report by the SSLG [3].

\section{Materials and Methods}

The project involved undertaking condition surveys of a representative sample of sandstone facades, selected in order to represent the range of stone buildings and stone types throughout the city [3]. The volumes of stone requiring replacement and the stonemason time and skills levels required for the repairs were calculated from these data, and extrapolated for the whole city. Characterisation of the types of sandstone required was undertaken by obtaining small samples of stone from selected buildings, followed by petrographic analysis to determine the variability of stone present. Representative core samples of $\sim 45$ $\mathrm{mm}$ diameter were obtained from buildings using a portable diamond core drill. Samples were prepared as standard petrological thin sections, impregnated with blue dye resin to highlight porosity.

A methodology for the facade surveys was designed to allow the rapid assessment of a large number of facades in order to produce quantitative data from which volumes of stone for repair were calculated. A total of 234 building facades were selected for survey, from 114 statutory listed buildings and 120 unlisted buildings, chosen to represent a range of building types from different parts of the city. A number of other criteria were used in the selection of buildings in order to ensure a representative sample of facades, including age of a building, geographical distribution within the city, style of masonry construction and facade orientation. Full details of the methodology used for the project are given in the project report [3].

The results of the facade surveys were produced as digital images rectified to scale, with areas of stone decay digitally overlaid onto the image, using software to automatically calculate the areas of stone decay (Fig. 1). The urgency of the repairs were highlighted on the digital images using different colours, and a series of codes were used to show different types of stone decay. A series of decay categories were devised specifically for this project which are relevant to stone buildings in Glasgow, based on published schemes by a number of recognised workers e.g. [4,5].

\section{Sources of Stone Used for the Construction of Glasgow's Stone-Built Heritage}

The blonde sandstone used for the majority of stone buildings in Glasgow was obtained from a large number of quarries within and around the city, and varies widely in character and quality. Approximately 75 known (i.e. named) sandstone quarries of significant size and output were present in the Glasgow 
district, although there were probably many more smaller scale excavations [6-8]. As in many other cities, the earliest quarries were located close to the city centre and subsequently became infilled or subsumed by urban development, and essentially sterilised from further use. Most quarries probably supplied only the local neighbourhood, whilst a lesser number of larger quarries were more significant, supplying stone more widely and for more prestigious buildings. For example, a series of quarries at Bishopbriggs and Giffnock (both located on the outskirts of the city) produced high quality freestones that were used throughout the city, as well as transported widely to other areas of Scotland and overseas (e.g. Giffnock stone was shipped to Ireland). Towards the end of the 19th century so much construction was going on that blonde sandstone had to be obtained from large quarries further afield in the central belt of Scotland (e.g. Stirlingshire and Lanarkshire).

As many local quarries became depleted and were engulfed by urban expansion, the arrival of the railways allowed the importation of red sandstone from Ayrshire and Dumfriesshire in southwest Scotland. This stone type quickly established itself in the city and the quarries were new and large and could produce large quantities of high quality stone. The red sandstone was also relatively easily worked and (being of aeolian as oppose to fluvial origin) was relatively free from impurities such as mud, clay and carbonaceous material. It is also possible that the use of red coloured stone became a fashionable alternative to the blonde sandstone which had dominated the city from its earliest times.

The large variety and mixture of sandstone types used in Glasgow (both local and 'imported' sandstone) gives a particular character to the city. It also means that there is a large variation in performance of stone in the city, with some types more prone to decay than others. This variety of stone types means that particular care has to be taken in the repair of Glasgow buildings through careful identification of stone and the selection of appropriate currently-available matching stone. None of the original quarries in the Glasgow district and throughout the Scottish central belt that supplied blonde sandstone for the construction of Glasgow are open today, and only a few of the original red sandstone quarries in southwest Scotland are still active. Almost all the blonde sandstone currently used for repairs (and new build) in the city has to be imported from sandstone quarries in the north of England. Recent research into the performance of replacement sandstone in nearby Edinburgh (also dominated by local pale coloured Carboniferous sandstones) has shown that the use of replacement sandstone with different characteristics to the original sandstones can result in damage to the remaining historic sandstone masonry in a building [9]. The first step to an improved understanding of the importance of careful selection of appropriate replacement stone for repairs is to characterise the range of original stone types present [10], which is the aim of the present study.

\section{Results: Identification of Sandstone Types from Petrographic Analysis of Samples from Buildings}

A total of 126 samples of building stone were collected from 112 surveyed buildings. The samples were selected in order to obtain fresh and unweathered stone where possible. It is not the purpose of the study to investigate the detailed mechanisms of decay occurring in the stone, although some general observations have been made from the petrographic analysis. The objective of the analyses is to characterise the variety of original sandstone types used throughout Glasgow, in order to provide a framework to identify matching stone types of similar petrographic characteristics for future repair and maintenance. The samples underwent standard petrographic analysis based on the procedure detailed in BS EN 12407:2000 'Natural Stone Test Methods-Petrographic Examination' [11] involving both macroscopic (hand specimen) and microscopic (thin section) descriptions. Thin sections were examined in transmitted polarised light using a standard petrological microscope. Although it would be desirable to undertake more detailed analysis with testing of the samples (for example measurements of porosity and permeability) this was beyond the scope of the study, particularly with the large numbers of samples involved. The results are intended to provide a broad classification of the Glasgow sandstone varieties, 
and more detailed testing of stone may be undertaken for specific conservation and repair projects.

On petrographic grounds the 126 samples of sandstone from buildings have been divided up into ten different categories, six blonde and four red sandstone types. The samples from buildings were compared to archive specimens from historic quarries held in the rock collections of BGS, in order to identify, where possible, which quarries supplied the different types of stone.

\subsection{Blonde Sandstones}

In general terms the blonde sandstones are quartz-rich (typically N85\% quartz), with feldspar, micas and lithic components generally b10\%. They show a range of grain size and textures, and contain variable amounts of matrix minerals, carbonate (calcite and dolomite), iron oxides and clay minerals. Porosity is estimated at typically 15-20\%, and generally open or locally infilled by carbonate and clay minerals. Framework grains are cemented by grain impaction and silica grain overgrowth, and represents progressively increasing variation in grain size and weak interstitial cements from matrix minerals. All the blonde composition (i.e. decreasing maturity), and details of the sandstones typically have a very pale cream colour. In general different types are summarised below. The categories of blonde terms the range of blonde sandstone types from B1 to B5 sandstones are illustrated in Figs. 2 and 3.

Type B1 is a well sorted and mature, highly siliceous quartzose sandstone with a uniform texture, subrounded grains and a relatively high and open porosity (Fig. 3A). It has a very low content of mica and matrix minerals, with little or no carbonate and clay, and a fine to medium grain size and a very pale uniform grey-white colour. Type B1 sandstone is distinct and more mature than most blonde sandstones in the Glasgow area, and a number of specific quarries in the Glasgow and central Scotland area have been identified as having supplied this stone. This type of sandstone was also quarried further east in the Scottish central belt and was much used in Edinburgh (similar to Craigleith sandstone, see [12]). The B1 sandstone appears to have been used particularly for prestigious buildings in Glasgow, suggesting it was recognised as a superior stone and favoured over the more commonly used local Glasgow blonde sandstone (see Type 2 below). Samples in the BGS collections from a number of quarries in the Glasgow area and throughout the Scottish central belt show similar characteristics to the type B1 sandstones, namely Blochairn, Lochcraigs and Smithstone quarries in Glasgow; Craigash, Milngavie; Dunmore, Stirlingshire; Humbie, West Lothian; and Craigleith, Midlothian.

Types B2 and B2a comprise the typical Glasgow 'blonde' sandstone and are the most commonly used stone types in the city, estimated as occurring in $43 \%$ of the blonde sandstone buildings. They are typically uniform subarkose sandstones, medium or fine to medium grained with $80-90 \%$ quartz. Carbonate, clay minerals and iron oxides are almost always present, partially infilling the open porosity. They have a pale cream to light tan colour, commonly specked with brown-orange iron oxide grains. Weathered samples show deterioration and mobilisation of the carbonate and iron oxide component, resulting in a variable orange-brown overall colour (Fig. 2C), particularly in decayed stone or in some buildings that have been chemically cleaned. Type B2a has a more variable grain size and composition, and lower porosity due to matrix infills of iron oxide and clay minerals. Type B2 stone was produced by the quarries at Giffnock and Bishopbriggs, the principal sandstone quarries supplying the city in the late 19th century. Together, these quarries are likely to have supplied a very significant proportion of the sandstone used in Glasgow, and were used for many of Glasgow's best known buildings [7,8]. Comparison with specimens from the BGS stone collections shows that the following quarries, all from the Glasgow area, have similar petrographic characteristics to Type B2 sandstone: Avenuehead; Bishopbriggs quarries (including Huntershill); Blochairn; Germiston; Giffnock quarries; Hillhouse Muir; and Monksredding, Kilwinning. A number of quarries, some from further afield, produced stone similar to the Type B2a sandstone: Doghillock, Denny; Kirkburn, Cambuslang; Laverock Knowe, Airdrie; Muirhouse Farm, Glasgow; Plean, Falkirk; Polmont, Glasgow; and Woodhall, Glasgow. 
Type B3 sandstone is characterised by a more variable grain size (less well sorted), with a higher clay mineral content locally infilling the porosity (Fig. 3C). The content of clay minerals and carbonate is variable but greater than for stone types B1 and B2. Type B3 sandstones were produced from the following quarries in the Glasgow district: Auchenlea, Motherwell; Budhill, Shettleston; Chatelherault, Hamilton; and Dullatur, Glasgow.

Type B4 sandstones are a particularly distinctive variety of blonde sandstone, characterised by a laminated appearance of thin, dark 'ripple' laminae defined by concentrations of iron oxide, carbonaceous matter and mica (Figs. 2E and 3E). The sandstone is otherwise generally fine grained and relatively well sorted, with an open pore structure. Some examples are less laminated with a more uniform texture. Type B4 sandstoneisparticularlycommonin19thcentury buildings immediately to the west of the city centre and areas further west (e.g. Gilmorehill). The characteristics of the sandstone are similar to that produced from a number of quarries in west Glasgow: Partick; Craigton; and Woodside. These were probably relatively small quarries which mainly supplied only local areas.

Type B5 sandstone is a distinctive typically coarse to very coarse grained quartz-rich sandstone, with a poorly sorted 'gritty' texture (Figs. $2 \mathrm{~F}$ and $3 \mathrm{~F}$ ). The high porosity is variably infilled by clay minerals, carbonate and iron oxides. They are typically very pale in appearance and may show bedding. Partly because of its variably coarse grain size, the B5 stone would have been difficult to work as a building stone, and it is likely to have been quarried on a relatively small scale for local use. None of the major quarries in the Glasgow district is known to have produced this type of stone, and its occurrence is mostly restricted to buildings in outlying villages and country estates, especially on the south side of the city (e.g. Castlemilk and Carmunnock).

\subsection{Red Sandstones}

The samples of red sandstone from buildings have been divided into 4 types, based on petrographic characteristics. Types R1, R2 and R3 have characteristics suggesting they are aeolian in origin, and in general terms are highly quartzose with an open pore structure (high porosity) and a very low content of matrix minerals. They are typically well sorted with rounded grains and show common planar bedding. The framework grains have a thin coating of iron oxide, imparting a reddish colour to the stone, and generally have a well developed silica overgrowth cement. Type R4 is a more diverse group with variable characteristics and relatively high content of matrix minerals, suggesting a fluvial origin. The main characteristics of the four types of red sandstones, together with comments on their likely source quarries, are summarised below.

Type R1 is typically very fine to fine grained with a deep red colour, and commonly shows parallel laminated bedding although some samples are more massive. It is moderately well sorted with grains ranging from rounded to angular, and a variable fabric ranging from open to compact. Finer grained beds have more angular grains and a higher matrix content. The Type R1 sandstone samples are petrographically similar to the red sandstones from Corsehill, Cove and St Bees quarries in Dumfriesshire and northwest England.

Type R2 is fine to medium grained, moderately to well sorted with relatively well developed iron oxide grain coatings giving a strong orange-red colour. Samples have relatively high feldspar content and an open porosity. Planar bedding or thin parallel bedding laminae are common. Type R2 sandstone is similar to that produced at Corncockle quarry in Dumfriesshire. 
Type R3 sandstone is typically coarser grained, commonly showing a bimodal grain size of well rounded grains. Thin, irregular iron oxide grain coatings give a pale pink colour, it has a well developed silica cement, and typically contains lithic clasts. Samples generally have a bedded texture with thicker beds of coarse grain size, and thinner beds with a finer grain size. It is petrographically similar to stone from the Ballochmyle quarry in Ayrshire and Locharbriggs quarry in Dumfriesshire.

Type R4 represents a broader category of 'red' sandstone with a more variable character, typically relatively poorly sorted with a high matrix (clay) content and a variable purple- lilac-grey colour. It has a lower and less open porosity than types R1 to R3. Samples commonly show a relatively poorly developed silica cement, and intergranular carbonate may be present. The R4 samples are petrographically similar to specimens from a number of quarries in fluvial Devonian rocks and quarries in the Carboniferous 'Barren Red Measures’ of the Glasgow district, such as Dalreoch, Bellshill and Bredisholm.

\section{Discussion: Supply of Blonde and Red Sandstone for Repairs and the Need to Reopen Quarries}

It is apparent that blonde sandstones with a wide range of petrographic characteristics were used for the construction of buildings in Glasgow. This is not surprising given the long time period (several centuries) over which the city developed, and the large number of documented quarries which supplied building stone to the city [7]. There is less petrographic variation in the type of red sandstones which are known to have been supplied from a smaller number of quarries, and over a shorter time period [8].

Because all the blonde sandstone quarries in the Glasgow area and the Scottish central belt are closed it will be necessary either to reopen some of these quarries or to use alternative stone with similar petrographic characteristics from other areas in order to obtain appropriate 'matching' sandstone types suitable for future repairs. Initial comparison of the six types of blonde sandstones with samples from active sandstone quarries throughout the UK has identified a number of quarries, mostly from Carboniferous rocks in the north of England which have reasonably similar characteristics to many of the Glasgow sandstone types. However, a number of the blonde sandstone types cannot be matched to any active quarries in the UK. Type B2 stone, which is present in 30\% of the sampled buildings, has characteristics of composition, grain size, texture and porosity which are different to the currently available sandstones. In addition, most sandstones from the north of England have a higher content of iron oxide producing an overall stronger buff colour compared to the pale 'blonde' stone which typifies many Glasgow buildings [9]. Furthermore, many of the currently available sandstones have a more variable grain size and are more compact, resulting in less porosity than the original sandstones. There is also no current quarry supplying stone with similar characteristics to type B4 sandstone, which has a distinctive dark ripple bedding lamination [3].

A study of the performance of replacement sandstones in nearby Edinburgh has shown that the use of replacement stone with different petrographic characteristics, in particular with lower porosity, can result in damage to the remaining original stone in a building [9]. Because of the lack of supplies of stone with characteristics similar to Types B2 and B4 it is clear that the question of reopening of quarries is an issue that needs to be addressed. To date there has been no modern assessment of building stone resources in the Glasgow area, nor reassessment of the large number of former building stone quarries, and it is a recommendation of this project that such studies are carried out [3].

For the four types of red sandstone there are a number of currently active quarries which can supply stone with similar petrographic characteristics. Several of these are the same quarries which supplied the original stone for construction in the late 19th and early 20th centuries (e.g. Locharbriggs, Corsehill and 
Corncockle quarries in Dumfriesshire). A few other alternative quarry sources in the north of England also supply stone with similar petrographic characteristics.

\section{Conclusions}

The different types of sandstone used for the construction of Glasgow have been characterised by petrographic analysis of samples from a representative set of buildings throughout the city. The samples have been categorised into ten different types of sandstone (six 'blonde' and four 'red' sandstone types) in order to create a framework to inform the selection of stone for future repairs. Whilst all of the original sandstone quarries in the Glasgow district and the Scottish central belt are closed, it is possible to identify a number of alternative sandstones with similar characteristics from currently active quarries, most in the north of England. However, several of the original sandstone types are not petrographically similar to stone from current quarries, and it considered essential to identify new sources of these stone types either by reopening the original quarries or by opening new quarries in stone of similar characteristics.

The study has shown that a wide variety of mostly local sandstone types were used in the city of Glasgow, giving its buildings a particular character. It is clear that the selection of replacement stone for repairs needs to take these petrographic differences into account, and it is considered that petrographic analysis of samples must be an essential prerequisite of any repairs project in order to identify the sandstone type present. It is hoped that this work will form a basis for the creation of a large petrographic database of stone types present in buildings and quarries, which can be used as a resource to guide future decisionmaking in the selection of appropriate replacement stone to ensure the future health of the stone-built heritage of Glasgow.

\section{Acknowledgments}

This research forms part of the Scottish Stone Liaison Group 'Glasgow Project', funded by Scottish Enterprise Glasgow (Construction Skills Action Plan), with Glasgow City Council, National Heritage Training Group and CITB-Construction Skills. The authors thank Dr Graham Lott (BGS) for reviewing the manuscript, and publish with permission of the Director, British Geological Survey NERC. 


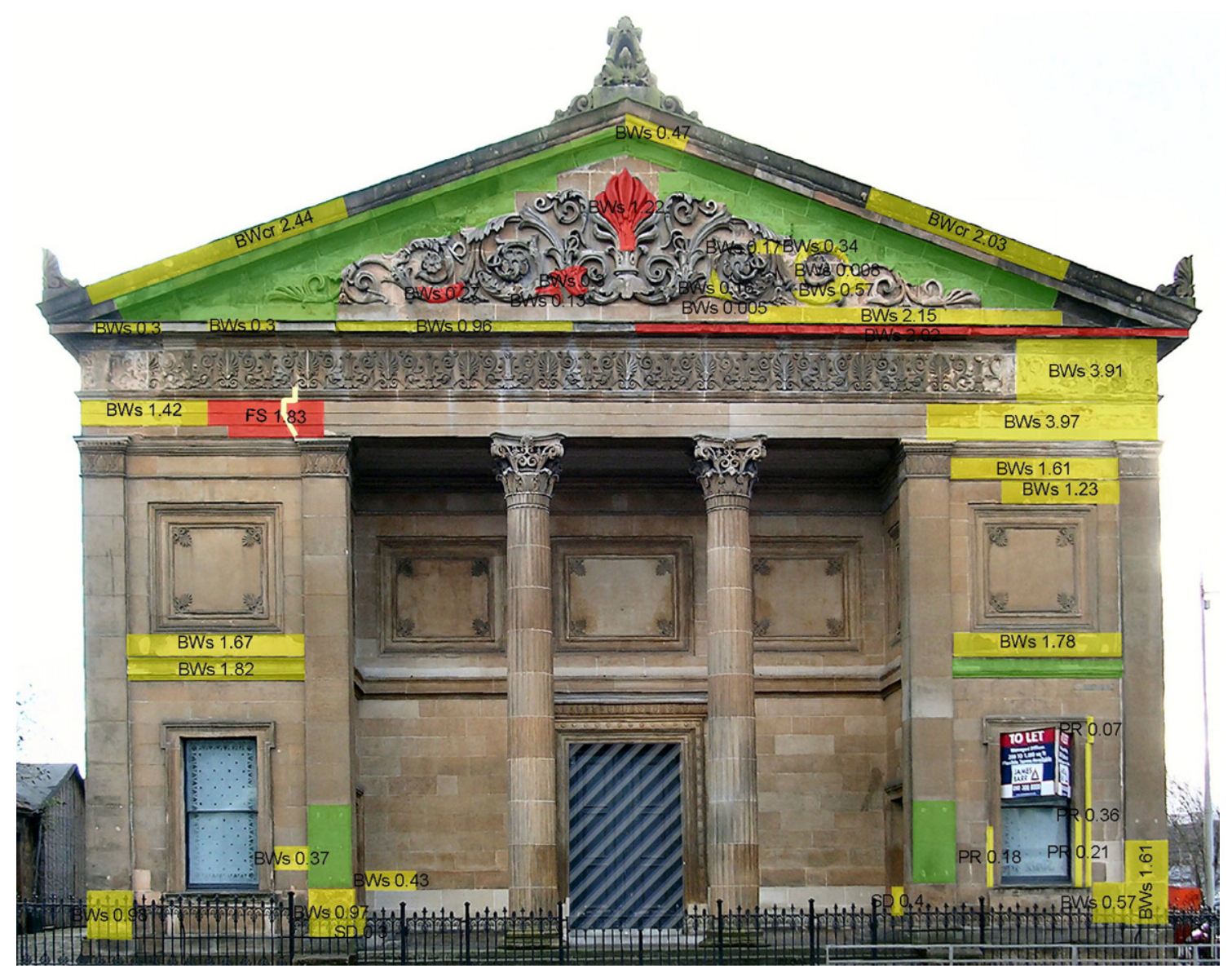

Fig. 1 - Rectified image of one of the buildings surveyed during the Scottish Stone Liaison Group 'Glasgow Project', showing parts of the façade overlain with different colours to signify repair requirements, and codes to represent various types of stone decay (former Duke Street Trinity Parish Church, built c.1858). 

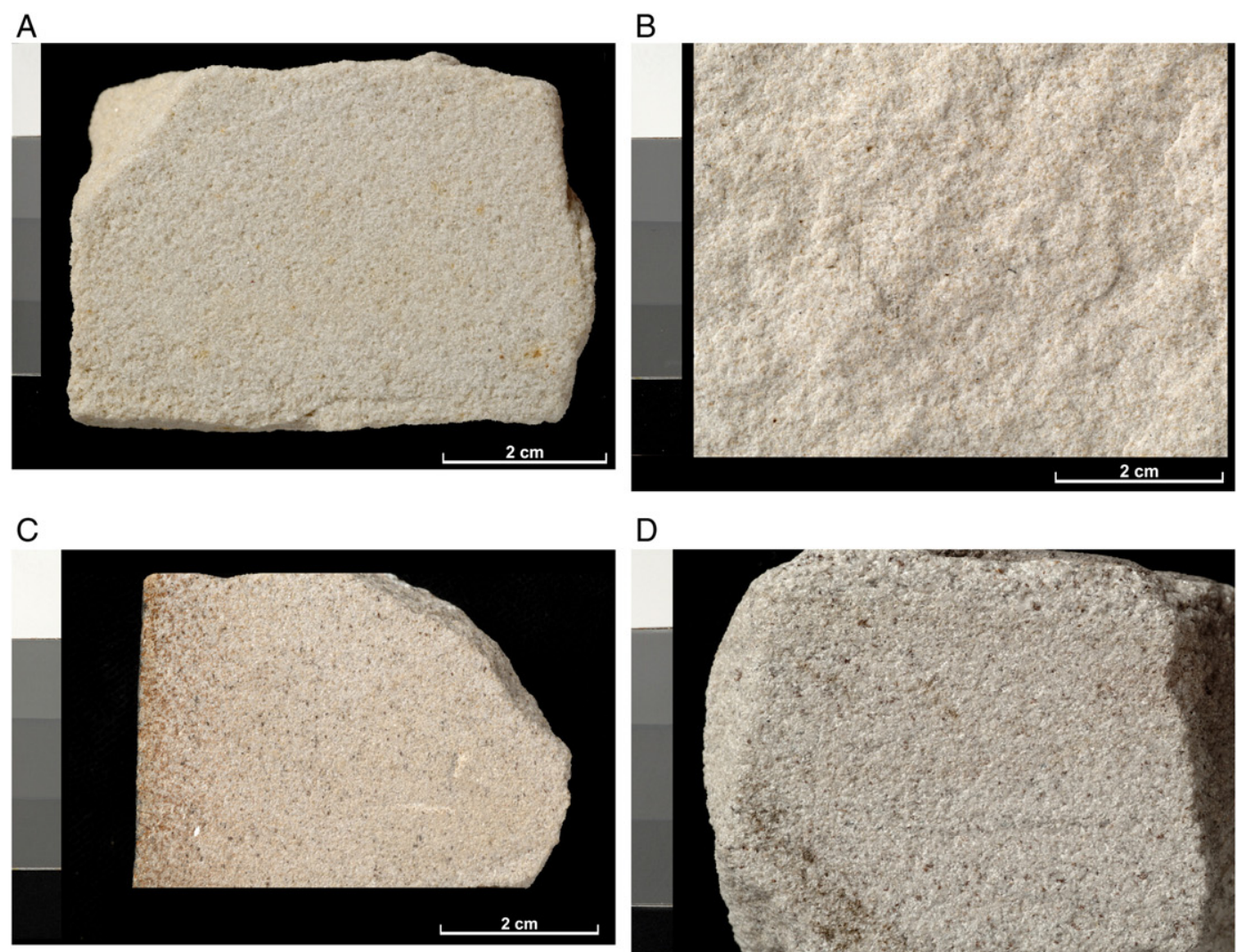

D
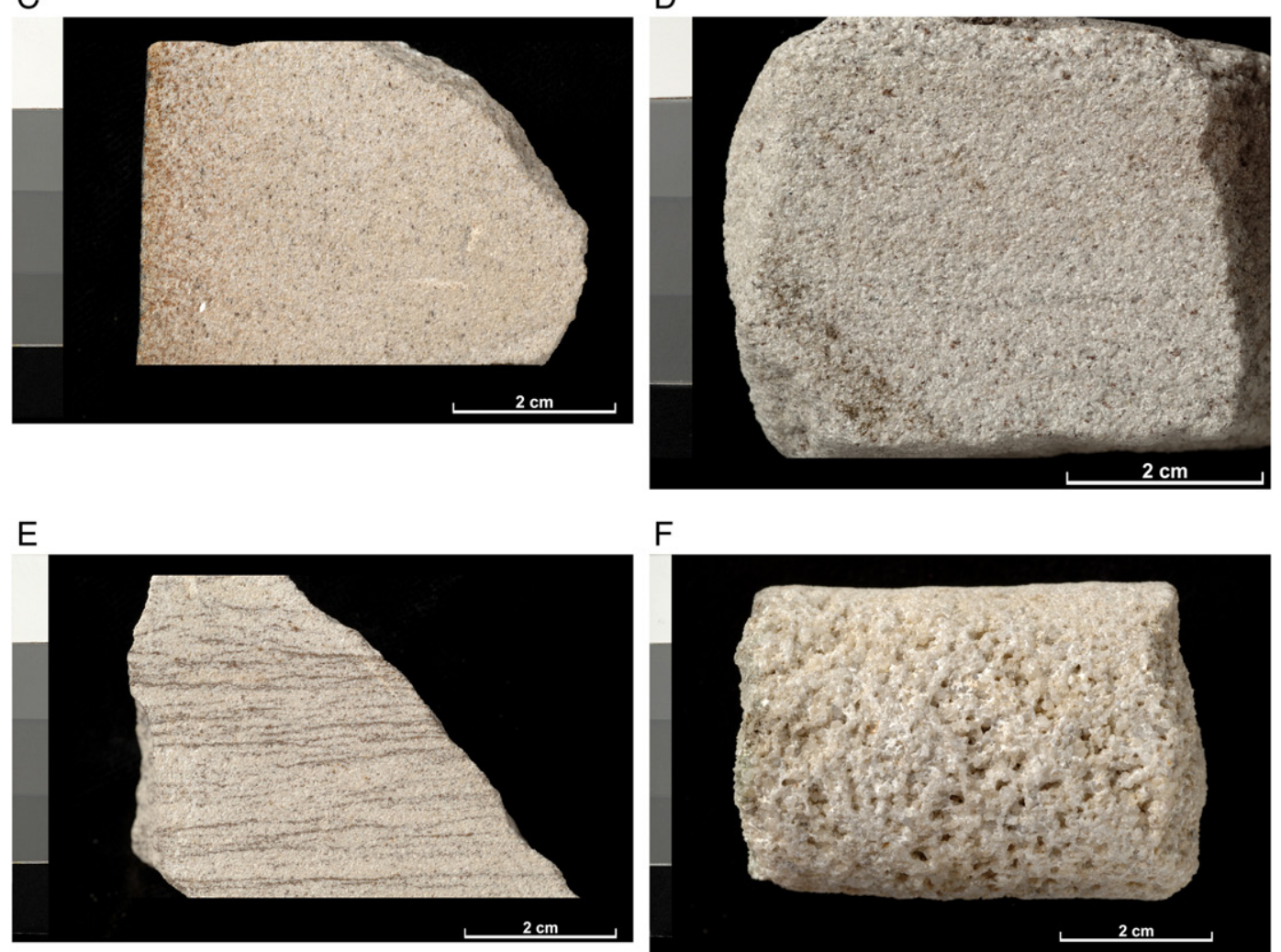

$\mathrm{F}$

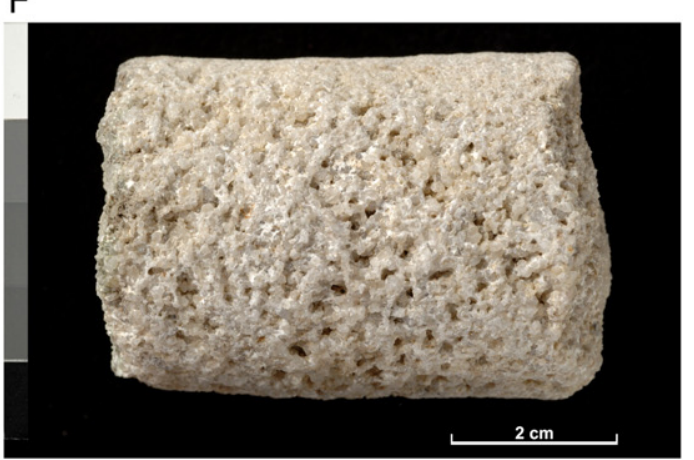

Fig. 2 - A. Type B1 sandstone showing typical very pale colour and uniform texture, typical of a highly quartzose sandstone (Blochairn quarry). B. Sample of sandstone from Giffnock quarry, typical of Type B2 sandstone (the most commonly used blonde sandstone in Glasgow), showing pale colour, uniform texture with small specks caused by iron oxide grains. C. Type B2a stone showing typical blonde colour and uniform texture but with impure composition caused by iron oxide and carbonate. Note the alteration of these minerals towards weathered surface to left hand side (Glasgow University Main Building). D. Type B3 sandstone showing variable grain size with relatively common opaque white clay minerals (kaolinite) and some darker colouration from iron oxides and carbonate (Budhill quarry). E. Type B4 sandstone showing characteristic dark 'wispy' bedding lamination within a fine grained very pale groundmass (Old Govan Docks building). F. Core sample of Type B5 sandstone showing very coarse grained nature with open pore structure and common white powdery clay minerals, probably kaolinite (Castlemilk Stables). 
A

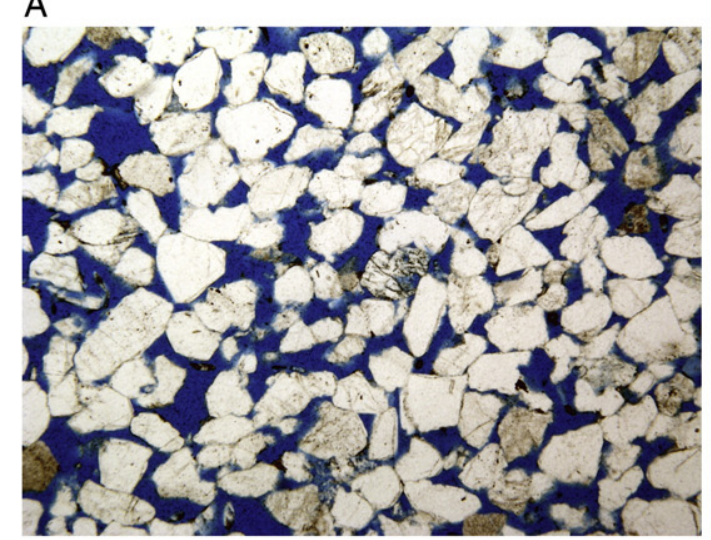

C

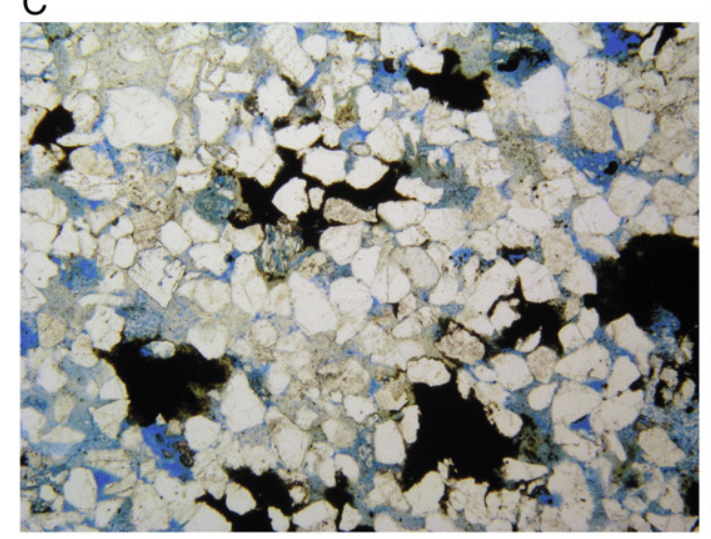

$\mathrm{E}$

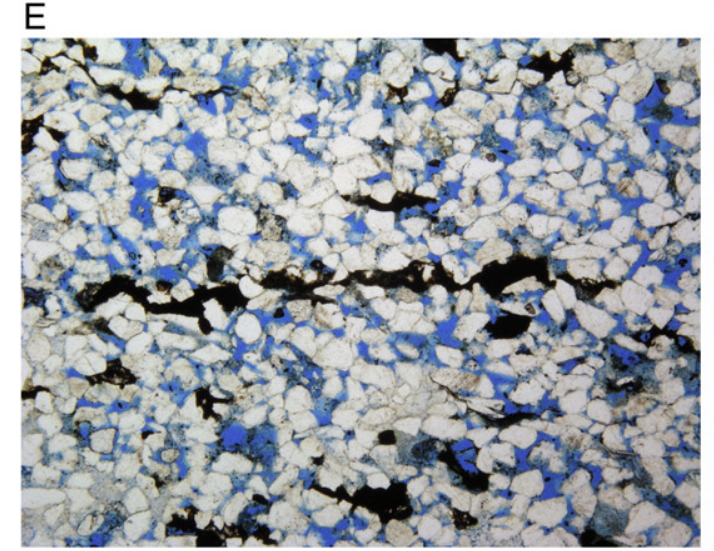

B
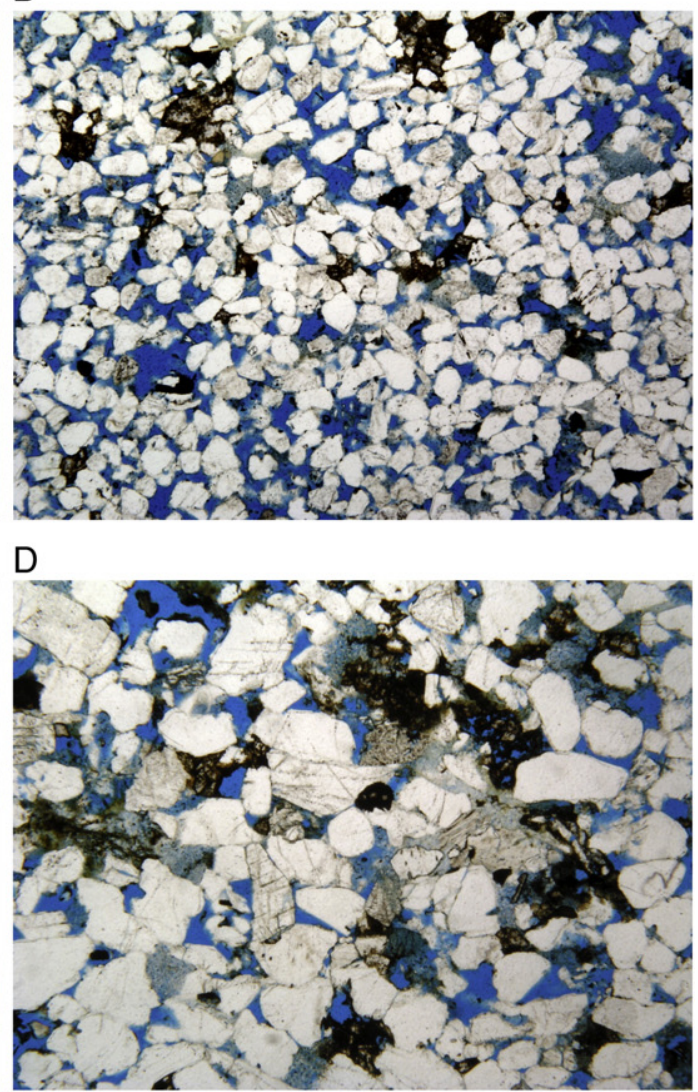

$\mathrm{F}$

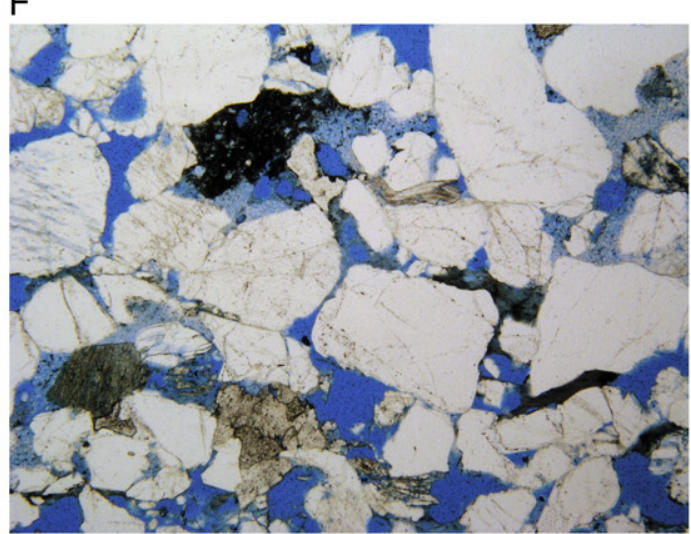

Fig. 3 - A. Type B1 sandstone showing quartz-rich, fine to medium grained, well sorted texture with relatively high and open primary porosity (Glasgow Cathedral). Image is e $0.3 \mathrm{~mm}$ across; plane polarised light; porosity highlighted by blue dye. B. Type B2 sandstone showing fine grained, well sorted grain distribution with open porosity locally infilled by clay minerals, dark iron oxides and altered carbonates (Springburn Nursery School). Image is e $0.3 \mathrm{~mm}$ across; plane polarised light; porosity highlighted by blue dye. C. Type B2a sandstone showing fine to medium grain size, with typical presence of relatively common iron oxide (black) and very fine grained clay minerals partially infilling porosity (Tramway Theatre). Image is e $0.3 \mathrm{~mm}$ across; plane polarised light; porosity highlighted by blue dye. D. Type B3 sandstone showing poorly sorted, fine to coarse grained texture with variable grain size and relatively variable composition with iron oxides, clay minerals and altered carbonate (Mansionhouse Drive). Image is e $0.3 \mathrm{~mm}$ across; plane polarised light; porosity highlighted by blue dye. E. Type B4 sandstone showing typical fine grained, well sorted texture with relatively high porosity, and elongate laminae of opaque iron oxides (black). Image is e0.3 mm across; plane polarised light; porosity highlighted by blue dye. F. Type B5 sandstone showing poorly sorted and coarse grained nature with iron oxide (black) and carbonate (Castle Street). Image is e0.3 mm across; plane polarised light; porosity highlighted by blue dye. 


\section{REFERENCES}

[1] Bluck BJ, Porter J. Sandstone buildings and cleaning problems. Stone Industries 1991;26(2):21-7.

[2] Webster RGM. Stone cleaning and the nature, soiling and decay mechanisms of stone. Proceedings of The International Conference held in Edinburgh, UK, 14-16 April 1992. London: Donhead Publishing; 1992.

[3] Scottish Stone Liaison Group. Safeguarding Glasgow's Stone Built Heritage: skills and materials requirements. Scotland: Scottish Stone Liaison Group; 2006.

[4] Esbert RM, Ordaz J, Alonso FJ, Montoto M. Manual diagnosis y tratamiento de materiales pétreos y cerámicos. Barcelona: Collegi d'Aparelladors, Arquitectes Tècnics de Barcelona; 1997.

[5] Fitzner B, Heinrichs K. Damage diagnosis on stone monuments-weathering forms, damage categories and damage indices. In: Prikryl R, Viles HA, editors. Understanding and managing stone decay, Proceedings of the International Conference 'Stone weathering and atmospheric pollution network (SWAPNET 2001)’. Charles University in Prague: The Karolinum Press; 2002. p. 11-56.

[6] Clough CT, Hinxman LW, Wilson JSG, Crampton CB, Bailey EB, Anderson EM, et al. The geology of the Glasgow District. Memoirs of the Geological Survey. Scotland: Geological Survey of Great Britain; 1911.

[7] Lawson J. Sandstone quarries in Glasgow. Proceedings of the Geological Society of Glasgow, vol. 124/125. Geological Society of Glasgow; 1983. p. 18-26.

[8] Lawson J. Topography and building materials. In: Williamson E, Riches A, Higgs M, editors. The Buildings of Scotland: Glasgow. Pevsner Architectural Guides. London: Penguin Books; 1990. p. 5-15. [9] Hyslop EK. The performance of replacement sandstone in the new town of Edinburgh. Edinburgh: Historic Scotland Research Report. Edinburgh: Historic Scotland; 2004.

[10] Hyslop EK. Sourcing and selection of stone for repair. In: Henry A, editor. Stone conservation principles and practice. Shaftesbury: Donhead Publishing; 2006. p. 88-99.

[11] British Standard. BS EN 12407 Natural Stone Test Methods: Petrographic Examination. London: British Standards Institution; 2000.

[12] McMillan AA, Gillanders RJ, Fairhurst JA. Building stones of Edinburgh. Edinburgh: Edinburgh Geological Society; 1999. 